\title{
Coordinated Development of Vocational Schools and Local Government Based on Interactions Model
}

\author{
YANG Kangkai \\ Chongqing University of Arts and Sciences, Chongqing 402160 China \\ email: 648741832@qq.com
}

\begin{abstract}
To explore the role of vocational education and local government in the process of economic and social development in their respective roles, should be the important way of how to promote the connection of production and vocational education. Education structure is subject to social economy structure, it means that the former should adapt to the latter. The powerful regional characteristics of vocational education determine its harmonious coexistence with the development of local economic industries and technologies. The connotation of school-based collaboration is that vocational schools and local government play their respective comparative advantages. Local government supports the development of vocational education on key factors, sets up the bridge between vocational education and local industry development, and provides good institutional environment and financial support for the development of vocational education. Vocational schools need to focus on connotative development, improve the quality of personnel training in all directions, and constantly expand their own services to local economic and social development function. The collaborative development of two sides will be reasonable to promote the integration of production and vocational education in the way of market guidance, promotion of government and participation of vocational schools.
\end{abstract}

Key word: vocational education; local government; interaction; responsibility

\section{Introduction}

The different social economy structure in a region leads to different industries structure and technology structure, thus education structure should adapt to social economy structure. The relationship between vocational education and local government should be in the state of mutual promotion, restriction each other and harmonious symbiosis, and the collaborative development of the two sides needs them hand in hand together in order to be in the state of benign interaction. The present paper tries to seek the new mechanism of personnel trained by vocational schools and talents used by local government with cooperation among vocational schools, enterprise, campus, and community as a link by the carrier of coordination of vocational education and local government

\section{Connotation of coordination of vocational education and Local Government}

In the concept of coordination of vocational schools and region, vocational schools refers to secondary specialized school, Occupation senior middle school, technical school and institute of technology, university of staff and workers, senior technical schools, occupational technical colleges, also refers to applied technology college, teachers college of applied technology, vocational technical college, teachers college of technology. Although some local colleges and universities put forward the running strategies of coordination with local government, it's quite different from that as vocational schools because of their particular development goal such as discipline construction, therefore general colleges and universities are not included in this paper.

The region in coordination of vocational education and region refers to provinces but mostly district and county because of China's unique national conditions, the development level is quite unbalanced between north and south, west and east, the situation is of the same even in the same province. 
Taking Chongqing China as an example, it's economy development level is rather unbalanced in it's "one circle two wings" development strategy, in which one circle refers to urban area adding to districts and counties to which it takes an hour by bus, and two wings refers to towns cluster in Three Gorges Reservoir Area and towns cluster in south-east of Chongqing, the former makes Wanzhou center and the latter makes Qianjiang center. The development level is rather unbalanced between "one circle" and "two wings". In 2006, the per capita GDP in "two wings" is only equivalent to $54.3 \%$ and $52.7 \%$ respectively the average level of Chongqing. In 2007, farmers' per capita net income in "one circle" is $4379 \mathrm{RMB}, 47.4 \%$ more than that in "two wings". In recent years the economy in "two wings" develops rapidly, however, a huge gap still exists between "one circle" and "two wings". In 2010, GDP in "one circle" is 612.04 billion RMB, 77.5\% of the total GDP of Chongqing, the per capita GDP ratio "one circle" and "two wings" is 2.2 to 1 . According to Chongqing industrial layout planning, "one circle" will mainly develop the industries like car and motorcycle, equipment manufacturing, oil and natural gas chemical industry, materials industry, while energy and mineral resources of deep processing, salt and gas chemical engineering, natural gas chemical industry, machinery manufacturing, textile and clothing, green food processing, modern Chinese medicine and biological pharmaceutical processing in north-east of Chongqing, animal husbandry product processing, mineral resources processing, clean energy industry in south-east of Chongqing. Obviously, the above industrial layout planning has a strong orientation to talent training in different areas. Although in China it has already forms a reasonable and orderly mechanism for the flow of talents, yet development of local economy depends more on local human resources, that is on one hand to reduce the cost of investment, on the other hand to agree with the psychological characteristics of Chinese traditional culture. As the main development target for vocational schools is to train skilled personnel, offering intelligence supporting should be their responsibility. Based on the above mentioned, the government guides the local vocational education as a whole will be in favor of the targeted policy implementation.

The score of coordination of vocational schools and region is to promote harmonious development of regional economy, which needs perfecting regional interactions mechanism, making the most of respective comparative advantage, deepening division of labor and cooperation and breaking out regional economy formation formed by separate administration for a long time. The development strategy should adapt to particular needing, condition and opportunity, and in order to realize the regional strategic objectives the local government should strongly support local vocational schools by overall planning, classified guidance, should set up a vocational education system which adapt to development of local economy and society, and should build and share resources, create the brand of Education with vocational schools together.

\section{The relationship between vocational education and local economic society should be in the state of harmonious symbiosis.}

Vocational education has its unique regularity and certain independence, in a way it's independent, but it has close relationship with market economy, because resource allocation in the economic field decides resource allocation in educational field, and regional economy development level and investing quality that can be used in vocational education decides scale and speed of vocational education development. Investment in education is the most basic material base and condition of vocational education development, and the economic basis and development level decides investment amount in vocational education. At present in China, funding for vocational schools mainly comes from local finance. But in most of the western China, fiscal expenditure used in vocational education is a little because local government has a weak economic foundation and is in a low economic development level.

The students in vocational school mainly come from the local, and the local economic development level decides the public economic strength and consumption structure of residents 
family and restricts the level of family education investment growth fundamentally. Statistics show that the enrollment rate and investment gap of vocational education between developed countries and undeveloped countries can differ to dozens of times. Vocational education enrollment rates already became popular in domestic, such as Beijing, Shanghai, Shenzheng and other developed cities, and the western regions due to the level of economic development, scale and speed of vocational education development are much slower than that in center region and east of China.

New growth theory believes that technology and human capital has the spillover effect, its existence is a indispensable condition for economic sustainable growth. The two pillars of local economy development are human resources and innovation of technology. As a kind of capital factor, human has capital characteristic of investment and profitability. Both human resources and technology innovation are closely related to vocational education, which means vocational education has became the power source to advance the development of local economy. Chasing profit is the characteristics of the capital, human resources as the first resource of the knowledge economy, a large number of high-quality laborers are key factor for local economic development, it's significant for local economic and social sustainable development. As origin of high innovation and intelligence development vocational education is required to hold the important responsibility. With large quantities of high and new technology industry's rising all over China, the whole society demand on talented persons who adapt to the new industry and new technology will increase year by year, vocational schools are urgently required to provide all kinds of talents adapt to local industry and adapt to all kinds of talents with higher degree in order to promote local optimization of the industrial structure upgrade. But along with the optimization of the industrial structure upgrade and labor not adapting to current positions, it also requires vocational schools' non-academic education, which force them to constantly update the original knowledge and technology so as to improve the overall quality of workers in this region.

\section{Vocational School and Local Government Bear Their Responsibility Respectively}

At the time of developing and formatting it's characteristics of local economy, the local economic and social development presents integrated and comprehensive tendency, vocational schools in this area are needed coordinate with it, forming a vocational education system that adapts to local economic development. Vocational education structure affects the specification, quality, level of personnel training directly, and affects the layout of local industry structure as well as the regional innovation ability. Therefore it's quite difficult to establish reasonable corresponding relationship among local economic structure, industrial structure and structure layout of regional vocational education.

\subsection{The Responsibility of the Vocational Schools}

With the rapid development of vocational education and the expansion of higher education as well as the adjustment of economic structure, macro employment situation is more serious, so employment pressure further increases. In 2007, university graduates scale has reached 4.95 million, in 2008, 5.59 million, in 2009 and 2010, the number of university graduates has increased to more than 600 million respectively. So large scale the size of the college students group enter the job market, it makes some problems surface such difficult employment problem, the contradiction between schools' personnel training structure and requirements of industrial structure not in conformity, which will force vocational education level structure adjusted and changed through a variety of ways, including researching and forecasting demand on talented personnel in different levels, many kinds of profession due to local industry development, laying out local professional education structure reasonably, establishing vocational education system adapting to the local economy and society development, so as to meet the demand on talented personnel. Due to the long periodicity of personnel training and education structure adjustment needing a certain time, it requires that 
academic degree structure and major setting in vocational education in the region lead to economy development, playing a guiding role in the birth and development of emerging industry. Vocational schools merge themselves with local actively and make a sharp reaction to the development and changes of local economy, which can meet local demands and get rapid development as well.

Non equilibrium characteristic of economic development is reflected in the imbalance of regional economic and social development, and vocational education will inevitably suffer from restricting of economy development, which determines the diffidence of development levels and characteristics in different vocational schools. Therefore, vocational schools should according to their regional characteristics take advantage of the unique superiority in local area, on the basis of assessing their basic conditions, find the best combining site with social economic development area, set up professional and characteristic majors, and executive dislocation development so as to better promote the regional economic, political, scientific, technological and cultural coordinated development.

Accurate positioning can avoid it's role dislocation and play schools' unique role effectively. Vocational schools should have to find a suitable position in the orientation, develop practical talents as the key task, adhere to the service for the local economy society as the goal, according to local industry economic determine majors settings and curriculum development. In the pursuit of characteristics, the demand of local economic and social development is the guidance, vocational schools should aim at the local special demand, make some breakthrough in talents' knowledge structure and ability, talent training mode reforming and social demand needs should be combined, characteristics formed and brand created. Vocational schools should participate in education market competition actively, and get more education resources through education market, establish good images, so that the staffs and students realize consciously and psychological identify the schools, which can enhance the school centripetal force, build schools healthy operation and external expansion foundation, and the schools with good images tend to get recognized by the society and obtain government's support.

Schools are the member of social industry, on one hand schools as the subject of education industry have corresponding operation mechanism, on the other hand, inherent characteristics of modern science and technology and economy requires schools and enterprises cooperate and develop high and new technology and industry in common. Operation mechanism of a school refers to that a school coordinates it's own behavior independently, improves school internal running conditions and functions after receiving national education policy, information, market and other outside signals. Active alliance between vocational schools and enterprises can be realized by building science and technology enterprises through technology transformation, establishing high-tech industry base in which development research, results incubation and mass production works a whole, and form a situation of commonly ecological development between vocational schools and enterprises.

Vocational schools are important force to create local culture environment as one of the carriers of local culture, it is their own characteristic that determines they should find entry point to serve local society and establish a benign dialogue mechanism and interactive relationship with local society. Diffusing through their own culture, learning atmosphere, value orientation to local, vocational schools can increase far-reaching influence to the local national quality enhancement, at the same time, that help to solve problems such as urban and rural ecological environment and various problems needing natural science theory and technology research. While developing the school-enterprise and cooperating with local, vocational schools should actively seek the way and model of cooperation with enterprises and group, and form a pattern that culture serves economy development and promote the harmony between local economic construction and cultural development. In the process of development, vocational schools should absorb the advanced elements of local culture, refine their spiritual culture, regulate their own behavior culture, improve their environment culture, promote schools core competitiveness, and enhance the vitality and strength of the school. 


\subsection{The responsibility of local government}

Talents cultivated by vocational schools mainly serve the local economy construction directly, as the biggest beneficiaries, local governments should share the education cost more than other institutions. Developing vocational education can make local government obtain macro-economic efficiency, and vocational education plays a significant role in culture accelerating, development of science and technology, improving workers' quality, improving labor productivity, promoting economic growth and social progress. Therefore ,the local government should play macroeconomic regulation and controlling function, adjust the development rate of various levels vocational schools, realizing rational layout of vocational education scale structure, discipline structure and form structure, establish a vocational education system which adapts to the local economic and social development, promote education system ordering. The local government should increase in capital, policy system and service quality to local vocational schools. As a strong supporter to local vocational education, when making regional economic and social development planning, local government should give a full consideration to the coordinated development of science and technology, education, society and culture, create a condition and opportunity for vocational schools to participate in the construction of local economy, science and technology and public utilities, build a bridge of communication and cooperation between vocational schools and local society. Local government should strengthen the service functions further, realize the diversification of vocational education running mode, fully mobilize the enthusiasm of the social participation, form a situation of vocational education running across different systems and regions, domestic and foreign, public and private. Local government also should offer key support for the development of vocational education in the land, tax preferential policies, cultivate and better information market, talent market and culture market, etc. All the above mentioned are key factors and important external power for the development of local vocational education.

Through the market mechanism, the government achieves mutual communication between vocational education resources and all kinds of production factors in local, and achieves an optimal configuration. Local and vocational schools realize sharing in talents, science and technology, culture, sports facilities, promote organic fusion of the regional vocational education with local environment, population, politics and economy, and condense powerful local competitiveness. The local government and schools in the jurisdiction co-construct and share library, gymnasium and other large science and technology culture, sports facilities, spread scientific and cultural knowledge to the public as well as ideological and moral concepts and healthy and civilized lifestyle. Cooperation among vocational schools is encouraged through establishing joint conference system between vocational schools and the local, based on the principle of the complementary advantages and common development, vocational schools should make all-round cooperation such as in teaching, scientific research, industry development and other areas, share talent resources and teaching resource, permit teachers to work and encourage students to choose optional courses within the schools in this region, and promote credit recognition each other .

In the industrialization process of vocational education, the market mechanism has limitation to difficultly overcome, if the "distortion" of education price arbitrarily regulate education market competition, it will inevitably lead to blind education industry behavior and market failure, therefore education market's operation goal tending to education industry system in self organization and regulation should be the following: vocational schools conscious action and the government's moderate macroeconomic regulation and controlling, making vocational education behavior 
reflecting necessary planning, regulating education market operation direction, correcting education market running deviation, supplementing the shortage of education market regulation mechanism is .

The government should adhere to it's own responsibility, as masters of most vocational schools, it works as policy makers and direct managers and supervisors, it's attribute of administrative direct management is decisive to vocational schools management. The government plays the decisive role in the resources allocation, and on this point, vocational schools seriously depend on the government. Nowadays, combination of comprehensive rating and special subsidy way is the main appropriation way for government to manage vocational schools, namely according to the basis of budget allocation way such as, regulation project, staffing plan, all expenses standard and number of students in school, which is not a good way to accelerate vocational school to face the market mechanism. The existing problems need the government to reflect how to not only guarantee the fairness of education, but meet the demand on diversity and particularity of educational education, the government should focus on total balance and long-term planning in the allocation of resources, the above problem on the micro needs the market to adjust, and the government should try to seek for a management mode of a guidance on the macro while not making indiscreet remarks on the micro.

Vocational schools and local government are a community of interests, local vocational education has the support of local government, it can grow faster and more stable, while local economic and social development can gain more high quality applied talents, sharing weal and woe, the benign interaction of them will lead to coordinated development.

\section{References}

[1] G. R. Luo \& X. Luo. To Achieve Coordinated Development of Vocational Schools and Local Government, Helongjiang Higher Education Research, Vol. 21 (2009) ,p2.

[2] D. Q. Chen. A Review of the German Dual Apprenticeship System, China Higher Education Research, Vol. 16 (2016), p95.

[3] Y. Q. Cui \& Y. L. Wu. The Function of Academic Degree System in Higher Vocational Education and Its Construction, Educational Research, Vol. 9(2015), p88.

[4] J. Zhu \& K. K. Yang. The Niche Construction of Vocational Education and Their Space Choice, Chongqing Higher Education Research, Vol. 4(2015), p73.

[5] L. J. Mo. Opportunities and Challenges: How to improve the Experimental Unit of Modern Apprenticeship in Vocational Colleges, Chongqing Higher Education Research Vol. 5 (2015), p90. 